\title{
Research Progress on Application of Organic Diamines and Their
}

\section{Derivatives}

\author{
Shouji Zhu $u^{1,2,3, a}$, Zhendong Zhao ${ }^{1,2, b^{*}}$, Shichao $\mathrm{Xu}^{1,2, \mathrm{c}}$, \\ Juanjuan Liu $^{2, d}$, Jianxin Jiang ${ }^{3, e}$ \\ ${ }^{1}$ Research Institute of Forestry New Technology, CAF, Beijing 100091, China. \\ ${ }^{2}$ Institue of Chemical Industry of Forest Products, CAF; Key and Open Lab. On Forest Chemical \\ Engineering, SFA, Nanjing 210042, China. \\ ${ }^{3}$ College of Material Science and Technology, Bejing Forestry University, Beijing 100083, China \\ azsj82633829@sina.com, bzdzhao@189.cn, '84836509@qq.com, \\ d435823074@qq.com, jiangjx@bjfu.edu.cn
}

Key words: Organic diamines; chemical synthesis; catalytic reaction; biological activity

Abstract. Organic diamines and their derivatives are important compounds in organic chemistry, which are useful and applicable in many fields. Among them, organic diamines have two $\mathrm{NH}_{2}$ groups, which can be enabled to react with aldehyde, acyl chloride and anhydride to give out schiff base, amide and amic acid, respectively, as well as to complex with metal ions to metal complex catalysts. Because of these chemical properties, organic diamines and their derivatives are used to be applied in chemical synthesis and catalytic reaction. In addition, they also have good biological activities.

\section{Introduction}

Organic diamines and their derivatives exist widely in nature. Because of the potential utilizations in different fields, there is great attention in the development of new organic diamines and their derivatives. There are two active functional groups (primary $\mathrm{NH}_{2}$ groups) in organic diamine, which can be enabled to react with many other compounds to give out different derivatives. For example, they can react with epoxy resin to supply of polymer in higher performance ${ }^{[1-8]}$, as well as with aldehyde, acyl chloride and anhydride to give out schiff base, amide and amic acid, respectively ${ }^{[9-11]}$. At the same time, they can also complex with metal ions and be used as catalyst in many reactions, such as Henry reaction, Machel addition reaction, aldol reaction and asymmetric oxidative coupling reaction ${ }^{[12,13]}$. Furthermore, a large number of literatures show that organic diamines and their derivatives have good biological activities ${ }^{[14-16]}$.

\section{Application to chemical synthesis}

\section{Synthesis of quinoxalines}

Quinoxalines are common nitrogen-containing heterocyclic compounds, which appear in many biologically and pharmaceutically active compounds ${ }^{[17-19]}$. They are synthesized from $O$-phenylendiamine compounds, ethyl pyruvate and $\alpha$-bromo ketone. In recent years, it has been focused on the synthesis of quinoxalines and their derivatives ${ }^{[20]}$. 


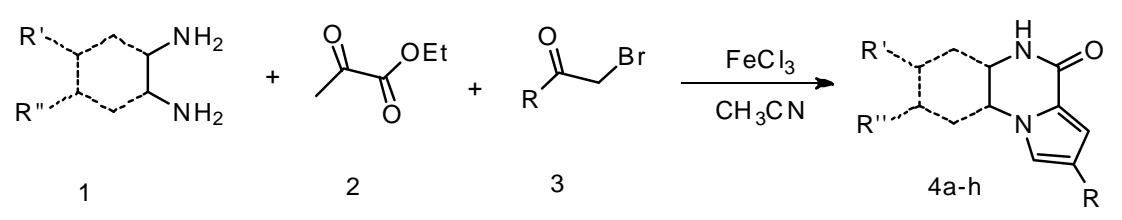

$\mathrm{R}=\mathrm{CO}_{2} \mathrm{Et}, \mathrm{Ph}, 4-\mathrm{Me}-\mathrm{C}_{6} \mathrm{H}_{4}, 4-\mathrm{Br}-\mathrm{C}_{6} \mathrm{H}_{4} ; \mathrm{R}^{\prime}, \mathrm{R}^{\prime \prime}=\mathrm{H}, \mathrm{Me}$

Scheme 1

Pyrrolo[1,2-a]quinoxalines were synthesized by Piltan ${ }^{[21]}$ via the three-component reaction of 1,2- phenlenediamine, ethyl pyruvate and $\alpha$-bromo ketone using $\mathrm{FeCl}_{3}$ as a catalyst (Scheme 1). Substituted quinoxalines were synthesized by Lian et. Al. ${ }^{[22]}$ with simple ketones and 1,2phenlenediamine as reactant, in which, bis-substituted quinoxalines were synthesized via a consecutive iodination/Kornblum oxidation/cyclization in the presence of $\mathrm{I}_{2} / \mathrm{CuO} / \mathrm{DMSO}$, and mono-substituted quinoxalines were synthesized via an iodination/cyclization/ aromatization in the presence of $\mathrm{I}_{2} / \mathrm{CuO} / \mathrm{K}_{3} \mathrm{PO}_{4} \cdot 3 \mathrm{H}_{2} \mathrm{O}$ (Scheme 2).

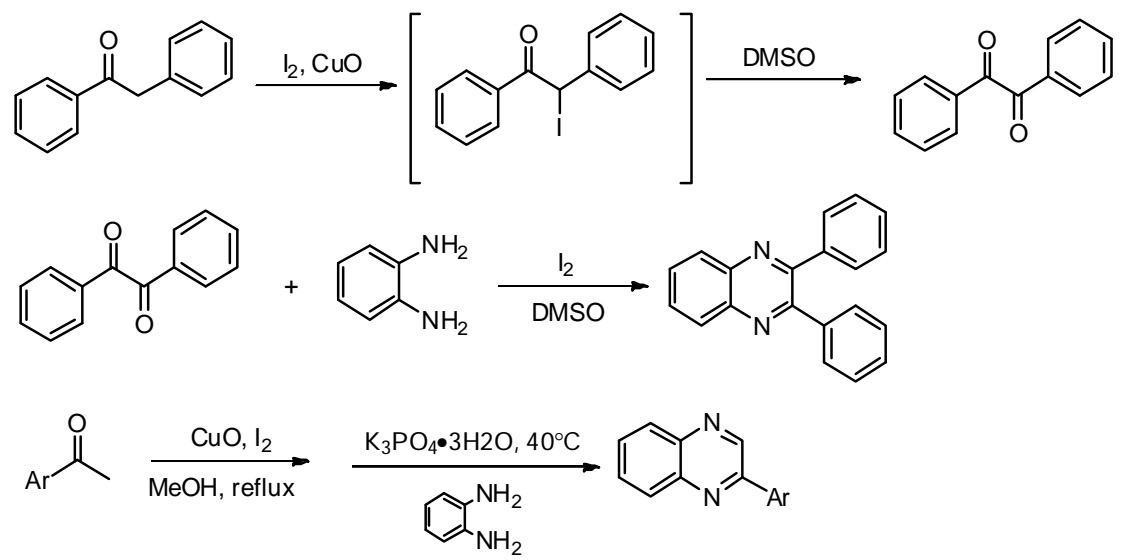

Scheme 2

\section{Synthesis of Schiff-base metal complexes}

Schiff base metal complexes play an important role in the development of the chemistry of chelate systems ${ }^{[23,24]}$. They are commonly used as catalysts in Henry reaction and Machel addition reaction. They also display wide range of applications in bioactivity, such as antibacterial and anticancer ${ }^{[25]}$.

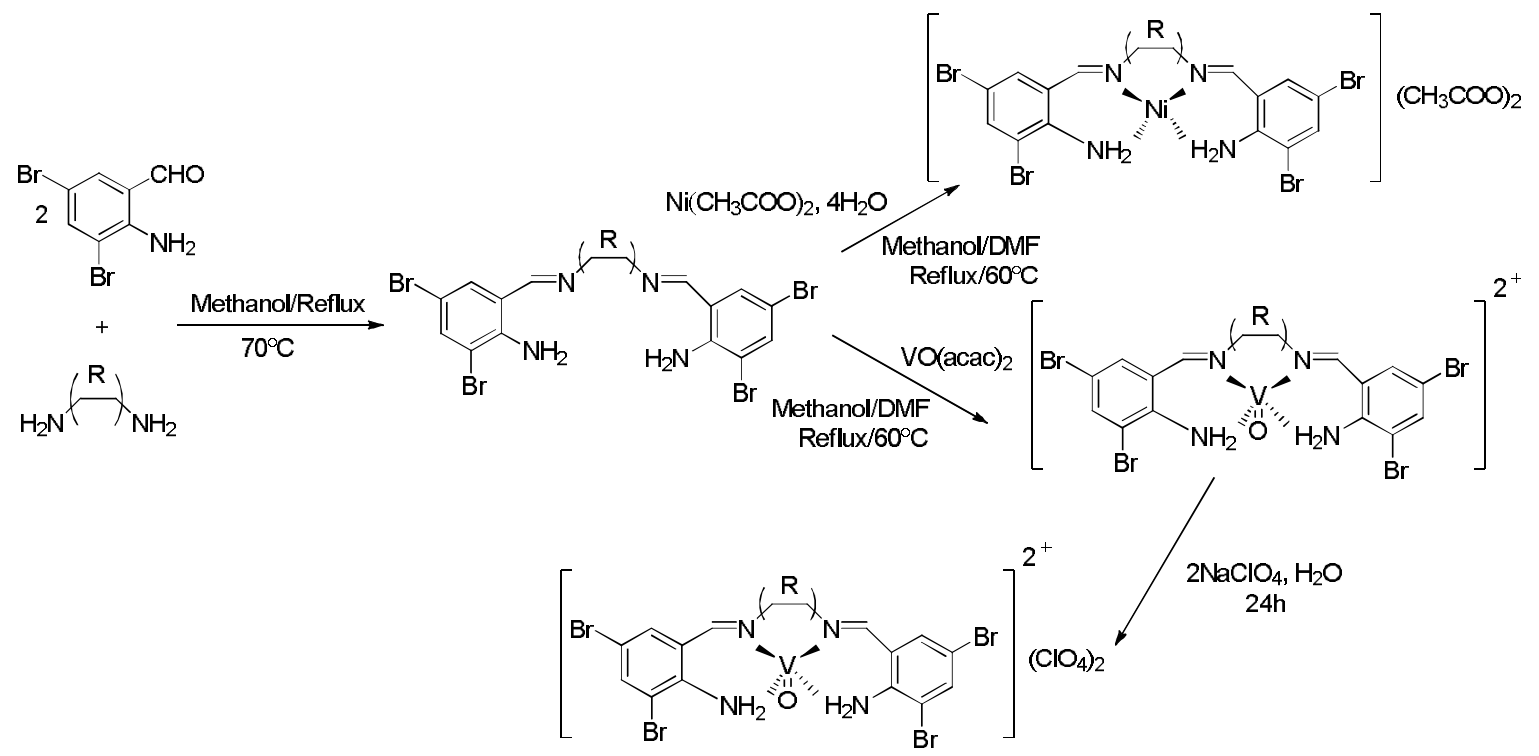

Scheme 3 
Mohammadi et al. ${ }^{[26]}$ reported that the tetradentate Schiff bases have been synthesized from 2-amino-3,5-dibromo-benzaldehyde and aliphatic diamines as reactants. And thereafter, the metal complexes have been synthesized. Additionally, the thermal stability of these compounds has been studied, and the thermal stability of oxovanadium(IV) complexes has been showed as follow: $\operatorname{VOL}^{2}\left(\mathrm{ClO}_{4}\right)_{2}>\operatorname{VOL}^{4}\left(\mathrm{ClO}_{4}\right)_{2}>\operatorname{VOL}^{3}\left(\mathrm{ClO}_{4}\right)_{2}>\operatorname{VOL}^{1}\left(\mathrm{ClO}_{4}\right)_{2}($ Scheme 3$)$.

\section{Synthesis of carbamates}

Carbamates are important pharmaceutical intermediates ${ }^{[27,28]}$, which are used to protect groups of amine functionality. The carbamatesare synthesized from diamines and DMC.

It was reported ${ }^{[29]}$ that dimethylhexane-1,6-dicarbamate could be synthesized from 1,6-hexanediamine with dimethyl carbonate. This reaction was catalyzed by $\mathrm{Bi}\left(\mathrm{NO}_{3}\right)_{3}$ in a yield of $84 \%$ at $353 \mathrm{~K}$ in $18 \mathrm{~h}$ (see Scheme 4).

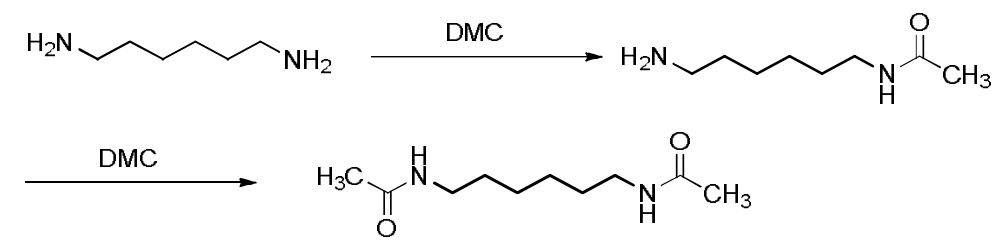

Scheme 4

\section{Synthesis of EDTA and its analogues}

Ethylenediamine tetraacetic acid (EDTA) and its analogues is important chelating agent, which can chelate with alkalis, lanthanide metal and transition metal to form water-soluble complex ${ }^{[30]}$.

Chen et al. [31] reported that the EDTN and its analogus were synthesized from diamino-containing compounds and hydroxylacetonitrile, which were further hydrolyzed to get EDTA and its analogues (Scheme 5).

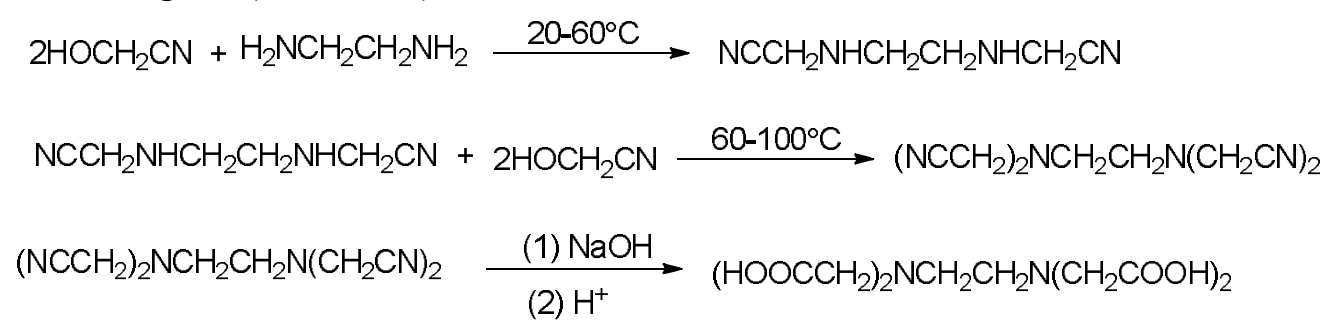

Scheme 5

\section{Application to catalytic reaction as catalysts}

Organic diamines and their derivatives exist widely in nature, which can catalyze many reactions, such as Henry reaction, Machel addition reaction, aldol reaction and asymmetric oxidative coupling reaction.

Four copper(II)/diamine complexes were synthesized and evaluated as catalysts in asymmetric Henry reactions by Canipa et al. Two of these complexes could effectively catalyze asymmetric Henry reactions ${ }^{[32]}$ (Scheme 6).

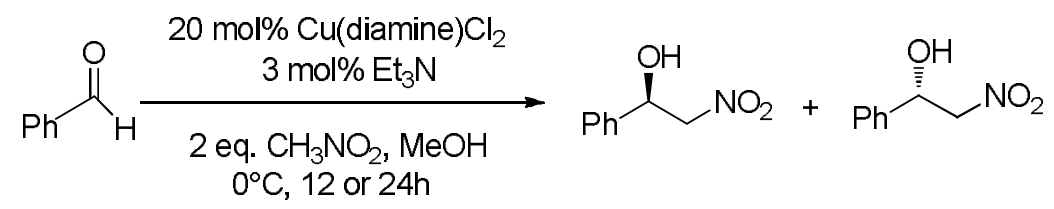

Schemel 6 
An organic diamine was synthesized and evaluated as a catalyst in Machel addition reaction by Mo et al., which was identified to exhibit better catalytic ability than the traditional chiral pyrrolidine catalysts in higher chemical yields ${ }^{[33]}$ (Scheme 7).

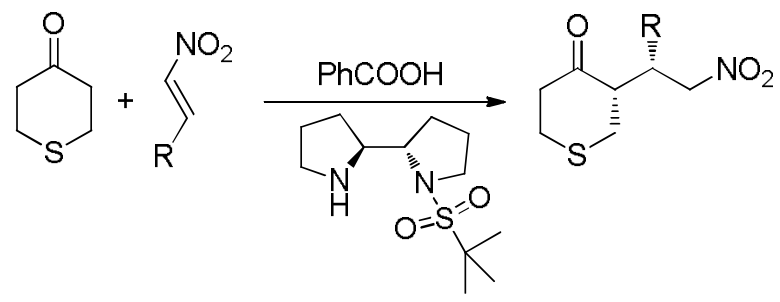

Scheme 7

Karikomi et al. realized the asymmetric coupling reaction of 2-hydroxybenzo[c] phenanthrenes using $\mathrm{Cu}$-chiral diamine as a catalyst under atmospheric air ${ }^{[34]}$. It was showed that $\mathrm{CuCl}$ cyclohexanediamine derivatives as catalyst was found to be highly effective to give the helical quinone derivatives in a good yield with high percent enantiomeric excess (Scheme 8).

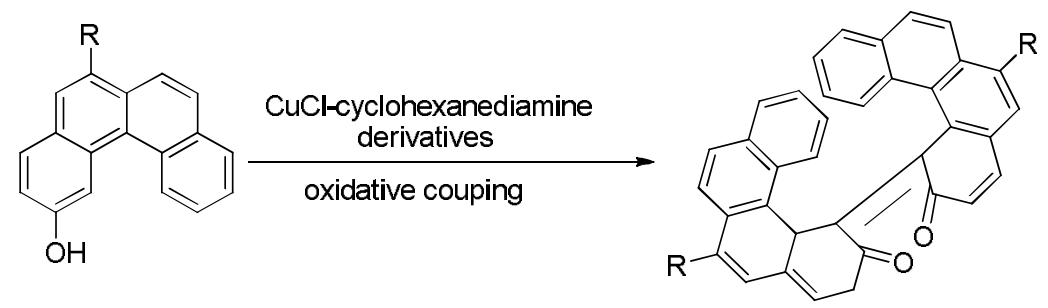

Scheme 8

It was reported that the enantioselective organocatalytic aldol reactions of ketones with various aldehydes were catalyzed by chiral 1,2-cyclohexanediamine basing on multifunctional ligands and functionalized 3-alkyl-3-hydroxy- indolin-2-ones was obtained in high yields ${ }^{[35]}$ (Scheme 9).

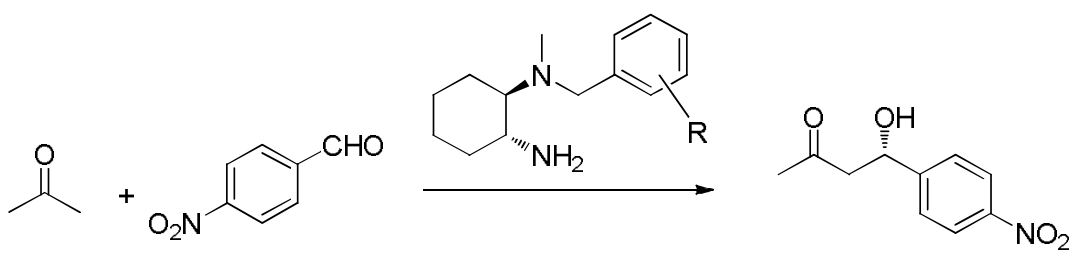

Scheme 9

\section{Application to bioactivity}

There are many organic diamines and their derivatives widely existed in nature, among which many of them have good bioactivity, such as antibacterial activity, anti-insect activity and cytotoxic activity.

A series of N,N-dibenzyl-cyclohexane-1,2-diamine derivatives were synthesized and against Gram-positive and Gram-negative bacterial strains were tested by Sharma et al. It was showed that there were seven compounds found to be more active than tetracycline and some of these derivatives had promising antifungal activity against Candida albicans, Candida glabrata and Geotrichum candidium ${ }^{[36]}$.

Two diamines were synthesized and testet against two isolates of Trichomonas vaginalis in vitro by Giordani et al. And it showed these two compounds could inhibit the parasite growth ${ }^{[37]}$.

5,6-heteroaromatically annulated pyridine-2,4-diamines have been evaluated against six human cancer cell lines in vitro and it was showed that benzo[g] annulated pyrido[2,3-b]indolediamines had relatively high cytotoxic activity ${ }^{[38]}$. 


\section{Conclusions and prospects}

Organic diamines and their derivatives are important compounds in organic chemistry, which are widely applied in the synthesis of medicine and pesticide, as well as in the catalytic reaction. In the other hand, many synthetic organic diamine compounds have a risk of toxicity to people, and it is better to look for some natural organic diamine compounds to instead of synthetic organic diamine compounds.

\section{Acknowledgments}

This work was supported by National Key Technologies R\&D Program (grant No. 2015BAD15B04).

\section{Reference}

[1] L. Li, H. Zou, M. Liang, et al., Thermochimica Acta. 597(2014) 93-100.

[2] K. Wei, G. Zhu, Y. Tang, et al., Journal of Polymer Research. 20(2013)1-7.

[3] A. Sabra, J.P. Pascault, G. Seytre, Journal of applied polymer science. 32(1986) 5147-5160.

[4] H.C. Anderson, Analytical Chemistry. 32(1960)1592-1595.

[5] X. Xiong, R. Ren, S. Liu, et al., Thermochimica Acta. 595(2014)22-27.

[6] J. Wan, C. Li, Z.Y. Bu, et al., Chemical Engineering Journal. 188(2012)160-172.

[7] G. Yang, S.Y. Fu, J.P. Yang, Polymer. 48(2007)302-310.

[8] W. Liu, Q. Qiu, J. Wang, et al., Polymer. 49(2008)4399-4405.

[9] C.P Yang, Y.Y Su, European polymer journal. 41(2005)249-258.

[10] S. Mehdipour-Ataei, L. Akbarian-Feizi, European polymer journal. 41(2005)1280-1287.

[11] Y. Nagasawa, Y. Matsusaki, T. Hotta, et al., Tetrahedron Letters. 55(2014)6543-6546.

[12] Y. Tang, X. Li, C. Lian, et al., 22(2011)1530-1535.

[13] B. Xu, L. Li, S. Gou, Tetrahedron: Asymmetry. 24(2013)1556-1561.

[14] M.V. de Almeida, M. Le Hyaric, G.W. Amarante, et al., European journal of medicinal chemistry. 42(2007)1076-1083.

[15] Z. Li, L. Jia, J. Wang, et al., European journal of medicinal chemistry. 87(2014)346-363.

[16] D. Gravestock, A.L. Rousseau, A.C.U Lourens, et al., European journal of medicinal chemistry. 49(2011)2022-2030.

[17] R.A. Smits, H.D. Lim, A. Hanzer, et al., Med. Chem. 51(2008)2457-2467.

[18] A. Furlan, F. Colombo, A. Kover, et al., European journal of medicinal chemistry. 47(2012)239-254.

[19] R. David, Expert opinion on investigational drugs. 7(1998)1063-1086.

[20] C.S. Yi, S.Y. Yun, Journal of the American Chemical Society. 127(2005)17000-17006.

[21] M. Piltan, Chinese Chemical Letters. 25(2014)1507-1510.

[22] M. Lian, Q. Li, Y. Zhu, et al., Tetrahedron. 68(2012)9598-9605. 
[23] S. Tella, V. Bekiari, V.G Kessler, et al., Polyhedron. 64(2013)77-83.

[24] A. Pladzyk, K. Baranowska, Journal of Molecular Structure. 1058(2014)252-258.

[25] L. Yang, S. Yan, D. Liao D, et al., Polyhedron. 14(1995)1565-1570.

[26] K. Mohammadi, S.S. Azad, A. Amoozegar, Spectrochimica Acta Part A: Molecular and Biomolecular Spectroscopy. 146(2015)221-227.

[27] P. Piccardi, Chimica \& Lindustria, 68(1986)108-117.

[28] T.T. Wu, J. Huang, N.D. Arrington, et al., Journal of agricultural and food chemistry 35(1987)817-823.

[29] R.G. Deleon, A. Kobayashi, T. Yamauchi, et al., Applied Catalysis A: General. 225(2002)43-49.

[30] M.H. Z, M.G. L, Y.G. D, et al., Strait Pharmaceutical Journal. 17(2005)13-15.

[31] G.H. C, Y.G. P, Guangzhou chemical industry. 37(2009)65-72.

[32] S.J. Canipa, A. Stute, P. O'Brien, Tetrahedron, 70(2014)7395-7403.

[33] L. Mo, H. Tang, Z.J. Yao, Tetrahedron. 69(2013)6897-6905.

[34] M. Karikomi, M. Toda, Y. Sasaki, et al., Tetrahedron Letters. 55(2014)7099-7101.

[35] L. Li, S. Gou, F. Liu, Tetrahedron: Asymmetry. 25(2014)193-197.

[36] M. Sharma, P. Joshi, N. Kumar, et al., European journal of medicinal chemistry. 46(2011)480-487.

[37] R.B. Giordani, M.V. De Almeida, E. Fernandes, et al., Biomedicine \& Pharmacotherapy. 63(2009)613-617.

[38] C. Willemann, R. Grünert, P.J. Bednarski, et al., Bioorganic \& medicinal chemistry. 17(2009)4406-4419. 